\title{
Bor Katkılı ZnO Nanopartiküllerin Sentezi ve Yapısal, Morfolojik, Optik Özelliklerinin Deneysel/Kuramsal İncelenmesi
}

\author{
Synthesis of Boron Doped ZnO Nanoparticles and \\ Experimental/Theoretical Investigation of Structural, \\ Morphological, Optical Properties
}

\author{
Yunus Kaya ${ }^{1 *}$, Enver Baydır², Ömür Aras ${ }^{3}$ \\ Geliş / Received: 23/10/2021 \\ Revize / Revised: 08/12/2021 \\ Kabul / Accepted: 13/12/2021 \\ $\overline{\mathbf{O Z Z}}$ \\ $\mathrm{Bu}$ çalışmada, sprey piroliz yöntemi ile farklı molar oranlarda $(\% 0,0.2,0.5,1$, ve 2$)$ bor katkılı $\mathrm{ZnO}$ \\ nanoparçacıkları elde edilmiştir. Katkısız ve katkılı ZnO nanoparçacıklarının karakterizasyonu, X-ışını kırınımı \\ (XRD) tekniği, yüzey morfolojisi Taramalı Elektron Mikroskobu (SEM) ve optik özellikler ultraviyole-görünür \\ bölge spektrumu ölçülerek yapılmıştır. XRD analiz sonuçları, wurtzite kristal yapıda $\mathrm{ZnO}$ nanoparçacıklarının \\ elde edildiğini göstermektedir. Bant aralığı enerjisi $\left(\mathrm{E}_{\mathrm{g}}\right)$ her bir numune için $2.98-3.15 \mathrm{eV}$ aralığında bulunmuş \\ ve katkı maddelerinin bant enerjisini artırdığı gözlemlenmiştir. Ayrıca 10 metal ve oksijen atomundan oluşan küme \\ yapıları yarı deneysel/pm6 yöntemi ile optimize edilmiş, kuramsal band boşluğu enerjisi hesaplanmıştır.
}

Anahtar Kelimeler- Bor Doplu ZnO Nanoparçacık, XRD, Bant Aralı̆̆, DFT

\begin{abstract}
In this study, boron doped $\mathrm{ZnO}$ nanoparticles in different molar ratios $(\% 0,0.2,0.5,1$, and 2$)$ were obtained by spray pyrolysis method. Characterization of pure and doped $\mathrm{ZnO}$ nanoparticles was performed by $\mathrm{X}$-ray diffraction (XRD) technique, Scanning Electron Microscopy (SEM) and UV-vis region spectrum. XRD analysis results show that $\mathrm{ZnO}$ nanoparticles in wurtzite crystal structure were obtained. The band gap energy $\left(\mathrm{E}_{\mathrm{g}}\right)$ was found in the range of $2.98-3.14 \mathrm{eV}$ for each sample, and it was observed that the additives increased the band energy. In addition, cluster structures consisting of 10 metal and oxygen atoms were optimized by the quasiexperimental/pm6 method, and the theoretical band gap energy was calculated.
\end{abstract}

Keywords- Boron Doped ZnO Nanoparticle, XRD, Band Gap, DFT

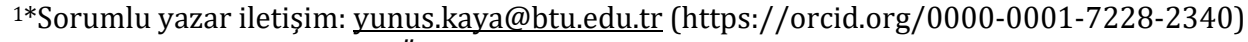

Kimya Bölümü, Bursa Teknik Üniversitesi, Bursa, 16310, Türkiye

2illetişim: enver.baydir@btu.edu.tr (https://orcid.org/0000-0003-1840-5797)

Kimya Mühendisliği Bölümü, Bursa Teknik Üniversitesi, Bursa, 16310, Türkiye

3Iletişim: omur.aras@btu.edu.tr (https://orcid.org/0000-0003-4577-028X)

Kimya Mühendisliği Bölümü, Bursa Teknik Üniversitesi, Bursa, 16310, Türkiye
} 


\section{GíRiş}

İndiyum kalay oksit (ITO) ve flor kalay oksit (FTO), şeffaf ve iletken elektrot malzemeleri olarak güneş pillerinde, düz panel ekranlarda ve enerji tasarruflu pencerelerde yaygın olarak kullanılmaktadır [1-4]. Bununla birlikte, indiyum metalinin maliyeti ve flor metalinin az bulunması son zamanlarda genişleyen optoelektronik cihaz pazarı için sorun yaratmaktadır. Bu nedenle, yeni ve uygun maliyetli alternatif şeffaf iletken oksitlerin geliştirilmesine ihtiyaç vardır [4,5]. Bu ihtiyacı karşılama potansiyeline sahip olan $\mathrm{ZnO}$, şeffaf iletken oksit olarak kullanılabilecek birkaç metal oksitten birisidir [6]. ZnO, UV bölgesinde yeni nesil optoelektronik cihazların, optik veya görüntüleme cihazlarının üretimi için en umut verici malzemelerden birisidir [7]. Ayrıca yüksek optik geçirgenlik, yüksek kırılma indeksi $(\mathrm{n} \approx 2.0)$ ve geniş bant aralığı $(3.37 \mathrm{eV})$ gibi yüksek optik özellikler sergilemektedir. Yüksek dielektrik sabitine sahip olması, çip kapasitörler veya karmaşık devrelerde kullanılan gecikme hatları için oldukça ilgi çekicidir. Bu nedenle, $\mathrm{ZnO}$, yüksek termal, mekanik ve kimyasal kararlılı̆̆ nedeniyle optoelektronik ve mikroelektronik cihazlar için giderek daha önemli hale gelmektedir [8-11].

Yarı iletken malzeme yüzeylerin farklı elementler ile katkılanması sonucunda meydana gelen etkileşim ile yüzeyler oldukça değişmektedir. Bu değişim farklı elektronik özellikler kazandırabilmektedir. ZnO iletken filmler üretmek için kullanılan tipik katkı maddeleri, periyodik tablonun grup III (B, Al, In, Ga) ve grup IV ( $\mathrm{Pb}$, $\mathrm{Sn})$ elementleridir [12]. Ayrıca, $\mathrm{ZnO}$ 'e indiyum [13], alüminyum [14], bor [4,5,15] gibi grup III iyonların katkılanması, malzemenin yapısal, optik ve elektriksel özelliklerini iyileştirdiği belirlenmiştir.

$\mathrm{ZnO}$ ince filmleri elde etmek için, kimyasal buhar biriktirme [16,17], magnetron püskürtme [18], darbeli lazer biriktirme [19-20], elektrokimyasal biriktirme [21,22], sol-jel tekniği [23-25] ve sprey piroliz yöntemi [7, 26-28] gibi teknikler vardır. Sprey piroliz (SP) tekniğinin diğer yöntemlere göre bazı avantajları vardır. Bu yöntem basit, ucuz bir tekniktir. Ayrıca bu teknik kullanılarak yüksek vakuma ihtiyaç duyulmadan geniş alanlı filmler üretilebilmekte ve üretilen filmler adım adım kontrol edilebilmektedir. SP kullanılarak üretilen $\mathrm{ZnO}$ ince filmler, çeşitli uygulamaların taleplerini karşılamak için çok çeşitli iyonlarla katkılanabilir [6].

Bu çalışmada, taşıyıcı gaz atomizer kullanarak farklı molar oranlarda bor katkılı $\mathrm{ZnO}$ ince filmler elde edilmiştir. Sprey piroliz tekniği ile hazırlanan Bor katkılı ZnO ince filmlerin yapısal, morfolojik ve optik özellikleri incelenmiştir. Ayrıca elde edilen hegzagonal yapılı $\mathrm{ZnO}$ molekülleri yarı deneysel yöntem ve pm6 taban kümesi kullanılarak modellenmiş, optik özellikleri kuramsal olarak da ortaya konulmuştur.

\section{MATERYAL VE METOT}

\section{A. Deneysel Çalışmalar}

$\mathrm{Bu}$ çalışmada, alüminyum altlık üzerine bor katkılı $\mathrm{ZnO}$ ince filmler sprey piroliz yöntemi ile hazırlanmıştır. Bor ve çinko kaynağı olarak sırasıyla borik asit $\left(\mathrm{H}_{3} \mathrm{BO}_{3}\right)$ ve çinko nitrat $\left(\mathrm{Zn}\left(\mathrm{NO}_{3}\right)_{2}\right)$ kullanılmıştır. Sprey piroliz uygulamasından önce alüminyum yüzeyindeki safsızlıklar aseton, etanol ve deiyonize su ile yıkanarak uzaklaştırılmıştır. Sprey solüsyonlarının bileşimlerinin molaritesi \%0, 0.2, $0.5,1$, ve 2 bor içerecek şekilde hazırlanmıştır. Hazırlanan solüsyonlar sırasıyla ZB0, ZB1, ZB2, ZB3, ZB4 olarak adlandırılmıştır. ZB0 olarak atfedilen $\mathrm{ZnO}$ ince film $0.2 \mathrm{M} \mathrm{Zn}\left(\mathrm{NO}_{3}\right)_{2}$ çözeltisinden sprey piroliz ile elde edilirken, aynı molaritedeki borik asit çözeltisinden farklı oranlarda bor katkılanması ile diğer ince filmler elde edilmiştir (ZB1-ZB4). Toplam hacmi $50 \mathrm{~mL}$ olarak hazırlanan çözeltilerin homojenliğinin sağlanması için 1000 rpm'de 20 dakika karıştırılmıştır. Tamamen homojen hale gelen çözeltiler Şekil l'de gösterilen çözelti tankına alınmıştır.

Püskürtme, yaklaşı $0.3 \mathrm{~mm}$ çapa sahip bir püskürtme memesi ile gerçekleştirilmiştir. Taşıyıcı gaz olarak $2.5 \mathrm{~mL} / \mathrm{dk}$ akış hızında ve 3 bar basınçta hava kullanılmıştır. Meme ile alt tabaka arasındaki mesafe yaklaşık 30 $\mathrm{cm}$ olarak ayarlanmıştır. Sistemdeki sıcaklı̆ğ kontrol etmek için bir sıcaklık kontrolörü kullanılmış ve sıcaklık $350^{\circ} \mathrm{Cde}$ sabitlenmiştir [29]. Alt tabakanın çok hızlı soğumasını önlemek için 10-15 saniyelik püskürtmeden sonra 10-15 saniye püskürtme durdurulmuştur. Böylece kaplamanın çatlamasına neden olan ani termal şokların önüne geçilmeye çalışılmıştır. 


\begin{tabular}{|c|c|c|}
\hline & $\begin{array}{l}\text { BŞEÜ Fen Bilimleri Dergisi } \\
8(2), 1064-1072,2021\end{array}$ & $\begin{array}{r}\text { BSEU Journal of Science } \\
\text { https://doi.org/10.35193/bseufbd.1013756 }\end{array}$ \\
\hline & & : 2458-7575 (https://dergipark.org.tr/tr/pub/bseufbd) \\
\hline
\end{tabular}

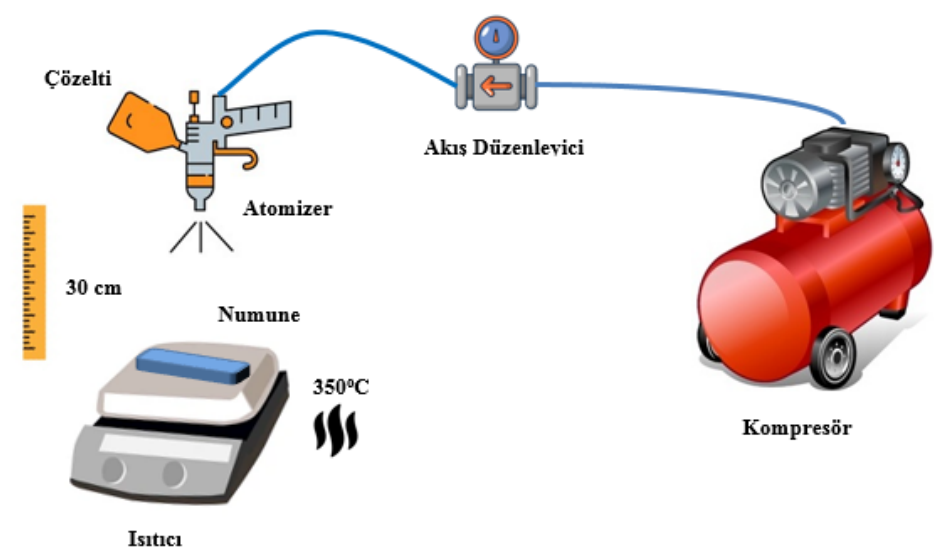

Şekil 1. Sprey piroliz kaplama sisteminin şeması

Üretilen ince filmlerin karakterizasyonu X-ışını kırınımı (XRD) tekniği ile yapılmıştır. Yüzey morfolojisi, Taramalı Elektron Mikroskobu (SEM) ile elde edilmiştir. Filmlerin optik geçirgenliği ise ultraviyole görünür bölge spektroskopisi kullanılarak ölçülmüş̧ür.

\section{B. Kuramsal Çalıșmalar}

Bu çalışmada, yapısal, optik ve HOMO-LUMO analizi için yarı deneysel yöntem ve pm6 temel seti [30] kullanılmıştır. Teorik hesaplamalar Gaussian 09 programı kullanılarak yapılmıştır [31]. Kümeler Zn10O10 ve Bor katkılı $\mathrm{ZnO}$ olarak modellenmiştir. Bor katkılı ZnO kümeleri, iki bor atomunun çinko yerine, oksijen yerine ve oktahedral boşluklara yerleştirilmesi ile 3 farklı model olarak oluşturulmuştur (Zn8B2O10, Zn10O8B2 ve

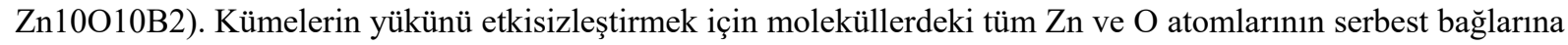
hidrojen atomu eklenmiştir. Literatürde yapılan küçük $\mathrm{ZnO}$ kümeleri gibi çeşitli metal oksitlerin teorik yapısal ve optik özellikleri olumlu sonuçlar vermiştir. Bu nedenle teorik hesaplamalarda bant aralığı değerlerinin hesaplanmasında güvenilir olduğu düşünülmektedir [32,33]. Moleküllerin geometri optimizasyonu, frekans ve moleküler orbital hesaplamaları aynı yöntem ve taban kümesi ile yapılmıştır. Ayrıca bant aralığı arasındaki farkın belirlenmesinde kullanılan sınır molekül orbitalleri, HOMO ve LUMO, Gauss view yazılımı kullanılarak görselleştirilmiştir [34].

\section{BULGULAR VE TARTISSMALAR}

Alüminyum metal yüzey üzerine sprey piroliz yöntemi ile kaplanmış farklı derişimlerde bor katkılı ve katkısız ZnO nanoparçacıklarının XRD desenleri Şekil 2'de sunulmuştur. Alüminyum metalin XRD pikleri 37, 44, 65.1 ve 77.7 derecelerde gözlenmiştir. Bu çok şiddetli piklerin dışındaki pikler katkılı ve katkısız ZnO nanoparçacıklarına aittir. Tüm nanopariküllerin XRD spektrumlarında 30.8, 33.6, 35.2 ve 82.1 derecede gözlenen pikler $\mathrm{ZnO}$ wurtzite yapısına bağlanabilir (Ref. Kodu: 00-036-1451). d değerleri ve bitişik kristal düzlemler arasındaki mesafeler (hkl) gibi wurtzite kafes parametreleri Bragg denkleminden $\lambda=2 \mathrm{~d} \sin \theta$ hesaplanmıştır. Elde edilen sonuçlar $\mathrm{ZnO}$ nano parçacıklarının oluştuğunu göstermektedir. $\mathrm{ZnO}$ nanoparçacıklarının bor ile katkılanmasında derişimin artması, özellikle Z3 ve Z4 numunelerinde gözlendiği gibi XRD piklerinin yoğunluğunun azalmasina neden olmuştur. 


\begin{tabular}{|c|c|c|}
\hline & $\begin{array}{l}\text { BŞEÜ Fen Bilimleri Dergisi } \\
8(2), 1064-1072,2021\end{array}$ & $\begin{array}{r}\text { BSEU Journal of Science } \\
\text { https://doi.org/10.35193/bseufbd.1013756 }\end{array}$ \\
\hline ERS & & : 2458-7575 (https://dergipark.org.tr/tr/pub/bseufbd) \\
\hline
\end{tabular}

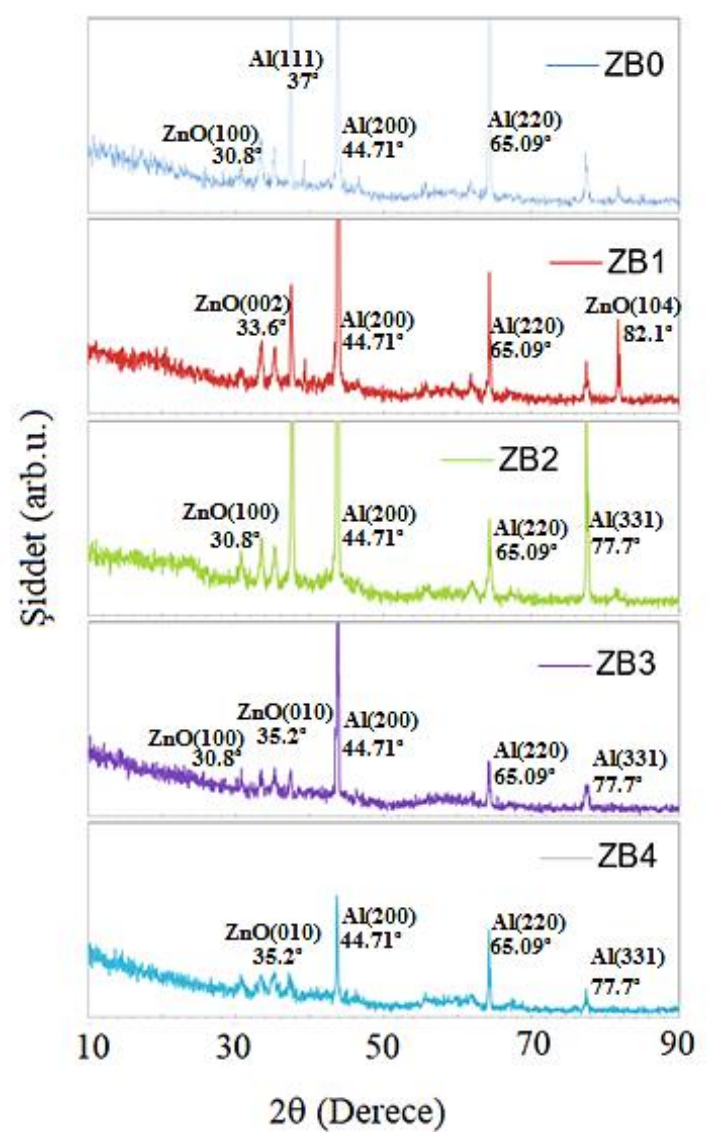

Şekil 2. ZB0, ZB1, ZB2, ZB3 ve ZB4 nanopatiküllerin XRD spektrumları

Katkısız ve bor katkılı ZnO nanoparçacıklarının yüzey morfolojisi, taramalı elektron mikroskobu (SEM) kullanılarak incelenmiştir (Şekil 3). SEM görüntüleri, alüminyum plakaların yüzeyinin nanoyapı ile iyi bir şekilde kaplandığını göstermektedir. ZB0 nanopartikülün SEM görüntüleri ZnO partiküllerinin küreler halinde tabaka üzerine kaplandığını ve homojen dağıldığını göstermektedir. Bor katkılarının miktarı arttıkça ZnO kümelerin morfolojisindeki değişim açıkça görünmektedir. Genel olarak, kendiliğinden gelişen nano yapının oluşumu, termodinamik ortam ve kristal büyümesi gibi parametrelere bağlıdır. Bu çalışmadaki tüm numuneler, sabit sıcaklıkta aynı büyüme parametreleri kullanılarak elde edilmiştir. Borun yarıçapı çinko iyonununkinden farklı olması nedeniyle $\mathrm{ZnO'nun} \mathrm{kristalleşme} \mathrm{özellikleri} \mathrm{bor} \mathrm{katkı} \mathrm{miktarına} \mathrm{bağlı} \mathrm{olarak} \mathrm{değişmiştir.} \mathrm{Artan} \mathrm{bor} \mathrm{katkısı}$ ile taneciklerin boyutları küçülmüş ve yüzeyde bir miktar gözenekler gözlenmiştir. Özellikle \%2 bor katkısının kullanıldığı ZB4 numunesinde ortalama tane boyutu ve yüzey pürüzlülüğünde azalma gözlenmiş ve daha düşük ışık saçılım özelliklerine sahip daha az dokulu filmler elde edilmiştir. 


\begin{tabular}{|c|c|c|}
\hline & $\begin{array}{l}\text { BŞEÜ Fen Bilimleri Dergisi } \\
8(2), 1064-1072,2021\end{array}$ & $\begin{array}{r}\text { BSEU Journal of Science } \\
\text { https://doi.org/10.35193/bseufbd.1013756 }\end{array}$ \\
\hline & & : 2458-7575 (https://dergipark.org.tr/tr/pub/bseufbd) \\
\hline
\end{tabular}

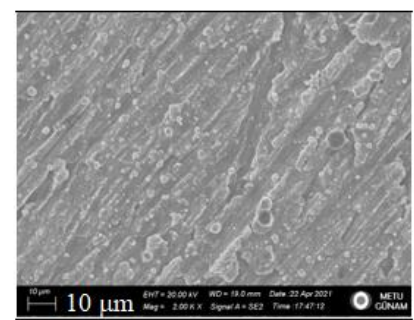

ZB0

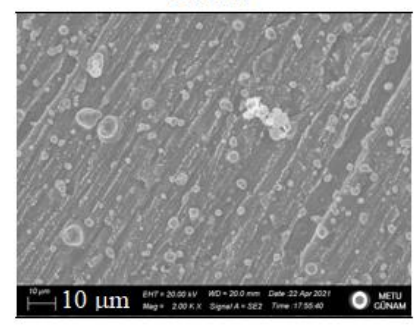

ZB2

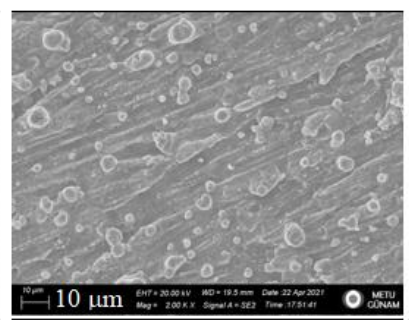

ZB1

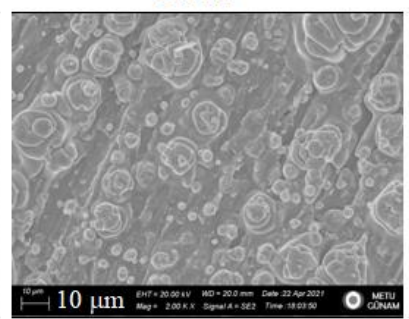

ZB3

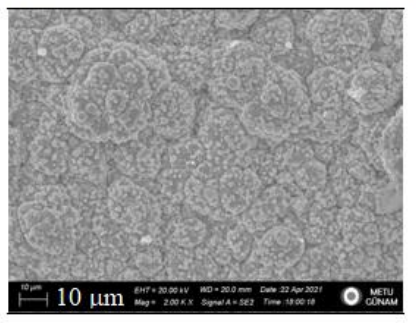

ZB4

Şekil 3. ZB0, ZB1, ZB2, ZB3 ve ZB4 nanopatiküllerin SEM görüntüleri

Ultraviyole-görünür bölge spektrumları, alüminyum tabakadan her numune kazınarak toz üzerinden 200$800 \mathrm{~nm}$ aralığında ölçülmüştür. Ultraviyole-görünür bölge spektrum ölçümlerinden elde edilen veriler Denklem (1)' de yerine konarak $\mathrm{ZnO}$ nanokristalin optik aralığının analizi elde edilmiştir.

$$
(\alpha h v)^{1 / n}=\beta\left(h v-E_{g}\right)
$$

$\alpha$ ve $\beta$ sırasıyla absorpsiyon sabiti ve bant kuyruk parametresidir, $E_{\mathrm{g}}$ optik bant aralığ enerjisidir ve $\mathrm{n}=$ 1'dir (doğrudan bant aralığı) [35]. Bant aralığı değerleri, $(\alpha h v)^{2}$ ve hv arasında elde edilen eğrinin lineer kısmının ekstrapolasyonu ile hesaplanır. ZB0, ZB1 ve ZB3 numuneleri için çizilen grafiklerden her bir numune için band boşluğu değerleri belirlenmiştir ve ilgili spektrumlar Şekil 4 'te verilmiştir. Elde edilen sonuçlara göre katkısız ZnO numunesinde (ZB0) gözlenen bant aralığı $2.98 \mathrm{eV}$ olarak ölçülmüştür. Katkılı numunelerde (ZB1, ZB2, ZB3 ve ZB4) band boşluğu değerleri sırasıyla 3.08, 3.10, 3.14 ve 3.15 eV olarak gözlenmiştir. 


\begin{tabular}{|c|c|c|}
\hline & $\begin{array}{l}\text { BŞEÜ Fen Bilimleri Dergisi } \\
8(2), 1064-1072,2021\end{array}$ & $\begin{array}{r}\text { BSEU Journal of Science } \\
\text { https://doi.org/10.35193/bseufbd.1013756 }\end{array}$ \\
\hline & & : 2458-7575 (https://dergipark.org.tr/tr/pub/bseufbd) \\
\hline
\end{tabular}
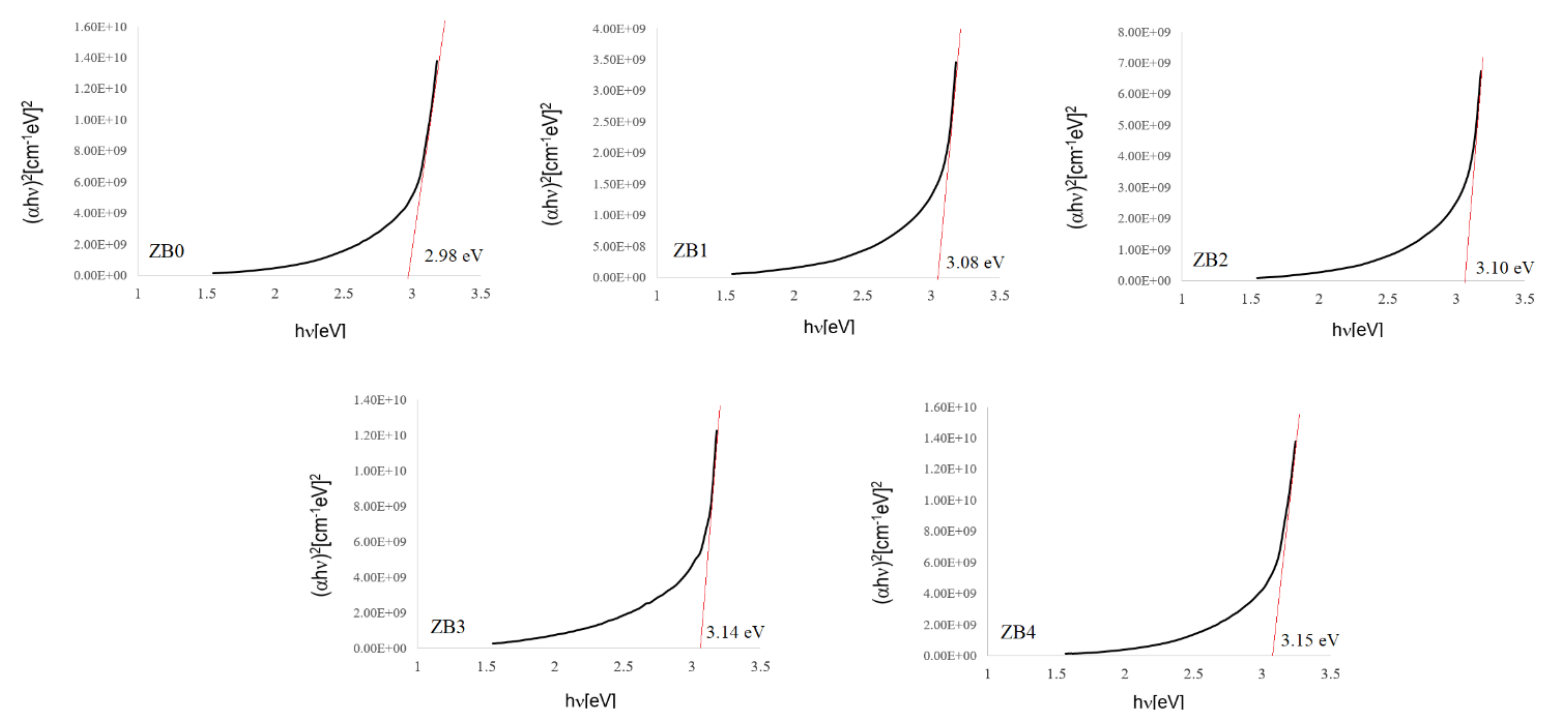

Şekil 4. ZB0, ZB1, ZB2, ZB3 ve ZB4 nanopatiküllerin optik band boşluğu

Elde edilen deneysel XRD sonuçlarından $\mathrm{ZnO}$ nanoparçacıklarının wurtzite kristal yapısında kristalleştiğini göstermiştir. Bu nedenle kuramsal hesaplamalarda wurtzite kristal yapısı kullanılmıştır. Katkısız, Zn10O10 kümesi ile çinko ve oksijen yerine bor atomunun yerleştirildiği Zn8B2O10 ve Zn10O8B2 kümeleri ile oktahedral boşluklara yerleştirilmiş Zn10O10B2 kümesi yarı deneysel/pm6 seviyesinde optimize edilmiştir [37]. Moleküllerin çıkış geometrisi olarak atomların X-ısıını deneysel x, y, z koordinatlarından elde edilen sonuçlar kullanılmıştır. Katkılı ve katkısız ZnO moleküllerinin optimize edilmiş yapıları Şekil 5'te verilmiştir.

Tüm optimize edilmiş hesaplamalarda, tüm kümelerdeki $\mathrm{Zn}$ ve $\mathrm{O}$ atomlarının serbest bağları hidrojen $(\mathrm{H})$ atomları ile tamamlanmıştır. Hidrojen atomları dışındaki diğer atomlar serbest bırakılarak hesaplamalar yapılmıştır. Sınır moleküler orbitalleri, HOMO ve LUMO, moleküllerin reaktivitesini belirlemek için çok önemli parametrelerdir. HOMO'lar bir elektron sunabilen ve bu yeteneği gösterebilen parametre iken, LUMO'lar bir elektron elde etme yeteneğini temsil eden elektron alıcılarıdır [36]. Yarı deneysel / pm6 düzeyinde hesaplanan Zn10O10, Zn8B2O10, Zn10O8B2 ve Zn10O10B2 kümelerinin HOMO ve LUMO orbital enerjileri arasındaki fark band boşluğunu vermektedir [38]. Katkısız $\mathrm{ZnO}$ için hesaplanan band boşluğu $2.98 \mathrm{eV}$ tur. İki çinko atomu ile borun yer değiştirilerek hesaplanan molekülün band boşluğu $3.87 \mathrm{eV}$, iki oksijen atomu ile yer değiştirilerek hesaplanan molekülün band boşluğu $3.21 \mathrm{ev}$ ve oktehedral boşluklara yerleştirilerek hesaplanan molekül kümesinin band boşluğu $4.09 \mathrm{eV}$ olarak hesaplanmıștır. Bu sonuçlar, $\mathrm{ZnO}$ nanoparçacıklarına bor atomu katkılanması ile elde edilen taneciklerin band boşluğunun arttığını desteklemektedir. Ayrıca, bor iyonları, wurtzite yapısında nanokristal yapıyı değiştirmeden oksijen atomlarının yerini aldıkları düşünülmektedir.

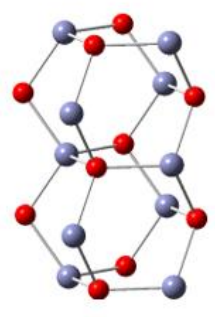

$2.94 \mathrm{eV}$

$\mathrm{Zn} 10 \mathrm{O} 10$

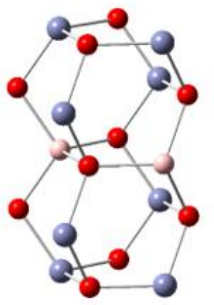

$3.87 \mathrm{eV}$

Zn8B2O10

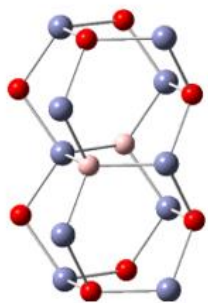

$3.21 \mathrm{eV}$

Zn1008B2

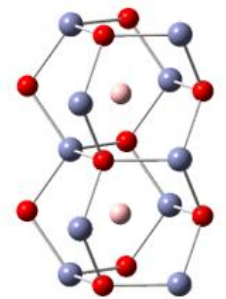

$4.09 \mathrm{eV}$

Zn10O10B2

Şekil 5. $\mathrm{ZnO}$ ve bor katkılı $\mathrm{ZnO}$ kümelerinin optimize molekül yapıları

Zn10O10, Zn8B2O10, Zn10O8B2 ve Zn10O10B2 kümelerinin aynı yöntem ve taban kümede yapılan hesaplamalar sonucunda elde edilen HOMO ve LUMO orbitalleri Şekil 6'da resmedilmiştir. Elektron yoğunluğu 
Zn10O10 kümesinin HOMO orbitalleri Zn atomunda lokalize olurken, bu yoğunluk LUMO orbitalinde O atomlarında doymuştur. HOMO ve LUMO molekül orbitallerinde elektron yoğunluğu, deneysel band boşluğu değerine yakın hesaplanan Zn10O8B2 kümesinde ise daha çok $\mathrm{Zn}$ ve B atomları üzerinde yer almaktadır.

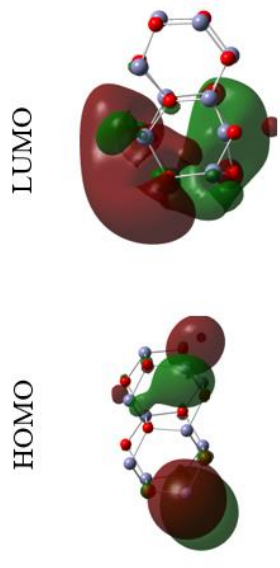

$\mathrm{Zn} 10 \mathrm{O} 10$
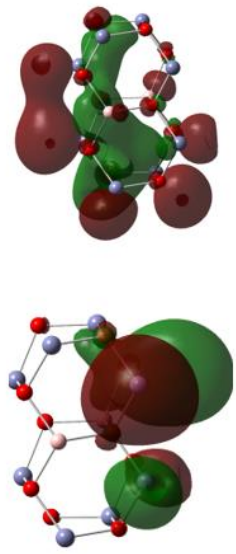

$\mathrm{Zn} 8 \mathrm{~B} 2 \mathrm{O} 10$
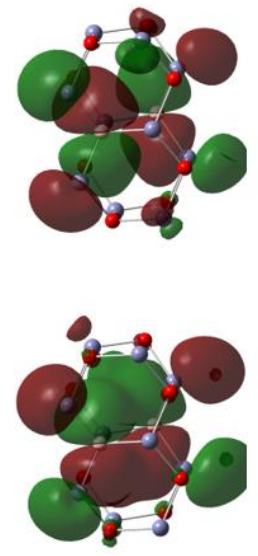

$\mathrm{Zn} 10 \mathrm{O} 8 \mathrm{~B} 2$
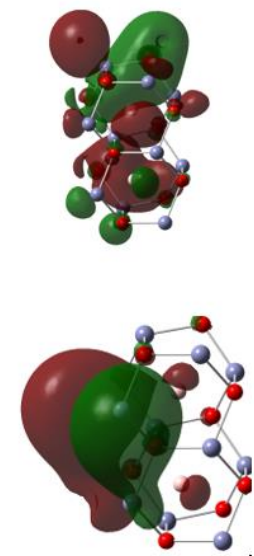

$\mathrm{Zn} 10 \mathrm{O} 10 \mathrm{~B} 2$

Şekil 6. Zn10O10, Zn8B2O10, Zn10O8B2 ve Zn10O10B2 kümelerinin HOMO ve LUMO şekilleri

\section{SONUCLAR}

Sprey piroliz yöntemi ile $\mathrm{B}$ katkılı $\mathrm{ZnO}$ nanoparçacıkları alüminyum plakalar üzerine başarılı bir şekilde kaplanmıştır. Elde edilen ince filmlerin yapısal, morfolojik ve optik özellikleri incelenmiş, bor ilavelerinin band boşluğu üzerine etkisi deneysel ve teorik olarak incelenmiștir. XRD sonuçları tüm nanoparçacıkların wurtzite yapıda kristalize olduğunu göstermektedir. Ultraviyole-görünür bölge spektroskopisi sonuçlarında elde edilen band boşluğu değerleri, deneysel olarak $2.98-3.15 \mathrm{eV}$ aralığında bulunmuş ve katkı maddelerinin bant enerjisini artırdığ gözlemlenmiştir. Katkısız ZnO için kuramsal band boşluğu $2.98 \mathrm{eV}$ olarak hesaplanırken, iki oksijen atomu ile yer değiştirilerek hesaplanan molekülün band boşluğu $3.21 \mathrm{ev}$ ve oktehedral boşluklara yerleştirilerek hesaplanan molekül kümesinin band boşluğu $4.09 \mathrm{eV}$ olarak hesaplanmıştır. Bu sonuçlar, ZnO nanoparçacıklarına bor atomu katkılanması ile elde edilen taneciklerin band boşluğunun arttığını desteklemektedir. SEM görüntülerinden katkı maddelerinin homojen ve düzenli dağıldığı tespit edilmiştir. Kuramsal olarak bor katkısı için üç model önerilmiş ve hesaplanan band boşluğu değerlerinden iki oksijen atomu yerine geçen bor atomu modelinde deneysel değere en yakın sonuç elde edilmiştir. Bu deneysel ve teorik çalışma, metal oksit kümelerinin optik davranışını analiz etmek için faydalı olacağı düşünülmektedir.

\section{KAYNAKLAR}

[1] Yakuphanoglu, F., Caglar, Y., Ilican, S., \& Caglar, M. (2007). The effects of fluorine on the structural, surface morphology and optical properties of $\mathrm{ZnO}$ thin films. Physica B: Condensed Matter, 394(1), 86-92

[2] Katusic, S., Albers, P., Kern, R., Petrat, F. M., Sastrawan, R., Hore, S., ... \& Gutsch, A. (2006). Production and characterization of ITO-Pt semiconductor powder containing nanoscale noble metal particles catalytically active in dye-sensitized solar cells. Solar energy materials and solar cells, 90(13), 1983-1999.

[3] Zaouk, D., Al Asmar, R., Podlecki, J., Zaatar, Y., Khoury, A., \& Foucaran, A. (2007). X-ray diffraction studies of electrostatic sprayed SnO2: F films. Microelectronics journal, 38(8-9), 884-887.

[4] Gaikwad, R. S., Bhande, S. S., Mane, R. S., Pawar, B. N., Gaikwad, S. L., Han, S. H., \& Joo, O. S. (2012). Roughness-based monitoring of transparency and conductivity in boron-doped $\mathrm{ZnO}$ thin films prepared by spray pyrolysis. Materials Research Bulletin, 47(12), 4257-4262.

[5] Kim, G., Bang, J., Kim, Y., Rout, S. K., \& Woo, S. I. (2009). Structural, electrical and optical properties of boron doped $\mathrm{ZnO}$ thin films using LSMCD method at room temperature. Applied Physics A, 97(4), 821-828.

[6] Bougrine, A., El Hichou, A., Addou, M., Ebothé, J., Kachouane, A., \& Troyon, M. (2003). Structural, optical and cathodoluminescence characteristics of undoped and tin-doped $\mathrm{ZnO}$ thin films prepared by spray pyrolysis. Materials Chemistry and Physics, 80(2), 438-445.

[7] Caglar, Y., Aksoy, S., Ilican, S., \& Caglar, M. (2009). Crystalline structure and morphological properties of undoped and Sn doped $\mathrm{ZnO}$ thin films. Superlattices and microstructures, 46(3), 469-475. 
[8] Ahmad, A. A., Alsaad, A. M., Al-Bataineh, Q. M., \& Al-Naafa, M. A. (2018). Optical and structural investigations of dip-synthesized boron-doped $\mathrm{ZnO}$-seeded platforms for $\mathrm{ZnO}$ nanostructures. Applied Physics A, 124(6), 1-13.

[9] Han, L. F., Fu, C. F., Liu, C., Liu, X. B., \& Xie, R. H. (2019). Influence of working pressure on the structural, optical and electrical properties of Cr-doped ZnO thin films. Journal of Electronic Materials, 48(5), 33173323.

[10] Goktas, A., Tumbul, A., Aba, Z., \& Durgun, M. (2019). Mg doping levels and annealing temperature induced structural, optical and electrical properties of highly c-axis oriented $\mathrm{ZnO}: \mathrm{Mg}$ thin films and $\mathrm{Al} / \mathrm{ZnO}: \mathrm{Mg} / \mathrm{p}$ Si/Al heterojunction diode. Thin Solid Films, 680, 20-30.

[11] Alsaad, A. M., Al-Bataineh, Q. M., Ahmad, A. A., Albataineh, Z., \& Telfah, A. (2020). Optical band gap and refractive index dispersion parameters of boron-doped $\mathrm{ZnO}$ thin films: A novel derived mathematical model from the experimental transmission spectra. Optik, 211, 164641.

[12] Chahmat, N., Souier, T., Mokri, A., Bououdina, M., Aida, M. S., \& Ghers, M. (2014). Structure, microstructure and optical properties of Sn-doped $\mathrm{ZnO}$ thin films. Journal of alloys and compounds, 593, 148-153.

[13] Ilican, S., Caglar, Y., Caglar, M., \& Demirci, B. (2008). Polycrystalline indium-doped ZnO thin films: preparation and characterization. Journal of optoelectronics and advanced materials, 10(10), 2592-2598.

[14] Dghoughi, L., Ouachtari, F., Addou, M., Elidrissi, B., Erguig, H., Rmili, A., \& Bouaoud, A. (2010). The effect of Al-doping on the structural, optical, electrical and cathodoluminescence properties of $\mathrm{ZnO}$ thin films prepared by spray pyrolysis. Physica B: Condensed Matter, 405(9), 2277-2282.

[15] Dai, Z., Shi, F., Zhang, B., Li, M., \& Zhang, Z. (2011). Effect of sizing on carbon fiber surface properties and fibers/epoxy interfacial adhesion. Applied Surface Science, 258(5), 1894-1894.

[16] Liu, Y., Li, Y., \& Zeng, H. (2013). ZnO-based transparent conductive thin films: doping, performance, and processing. Journal of Nanomaterials, 196521.

[17] Fang, X. S., Ye, C. H., Zhang, L. D., Li, Y., \& Xiao, Z. D. (2005). Formation and optical properties of thin and wide tin-doped $\mathrm{ZnO}$ nanobelts. Chemistry Letters, 34(3), 436-437.

[18] Wen, B., Liu, C. Q., Wang, N., Wang, H. L., Liu, S. M., Jiang, W. W., \& Chai, W. P. (2015). Properties of boron-doped $\mathrm{ZnO}$ thin films deposited by pulsed DC magnetron sputtering at different substrate temperatures. Applied Physics A, 121(3), 1147-1153.

[19] Kaur, G., Mitra, A., \& Yadav, K. L. (2015). Pulsed laser deposited Al-doped ZnO thin films for optical applications. Progress in Natural Science: Materials International, 25(1), 12-21.

[20] Holmelund, E., Schou, J., Tougaard, S., \& Larsen, N. B. (2002). Pure and Sn-doped ZnO films produced by pulsed laser deposition. Applied surface science, 197, 467-471.

[21] Tsin, F., Venerosy, A., Vidal, J., Collin, S., Clatot, J., Lombez, L., \& Rousset, J. (2015). Electrodeposition of $\mathrm{ZnO}$ window layer for an all-atmospheric fabrication process of chalcogenide solar cell. Scientific reports, 5(1), 1-8.

[22] Erturk, K., Isik, S., Aras, O., \& Kaya, Y. (2021). Investigation of structural, spectral, optical and nonlinear optical properties of nanocrystal CdS: Electrodeposition and Quantum Mechanical Studies. Optik, 243, 167469.

[23] Goktas, A. (2018). High-quality solution-based $\mathrm{Co}$ and $\mathrm{Cu}$ co-doped $\mathrm{ZnO}$ nanocrystalline thin films: Comparison of the effects of air and argon annealing environments. Journal of Alloys and Compounds, 735, 2038-2045.

[24] Tsay, C. Y., Cheng, H. C., Tung, Y. T., Tuan, W. H., \& Lin, C. K. (2008). Effect of Sn-doped on microstructural and optical properties of $\mathrm{ZnO}$ thin films deposited by sol-gel method. Thin Solid Films, 517(3), 1032-1036.

[25] Wen, B., Liu, C. Q., Wang, N., Wang, H. L., Liu, S. M., Jiang, W. W., ... \& Chai, W. P. (2016). Crystallization behavior and properties of $\mathrm{B}$-doped $\mathrm{ZnO}$ thin films prepared by sol-gel method with different pyrolysis temperatures. Chinese Journal of Chemical Physics, 29(2), 229-233.

[26] Mhamdi, A., Ouni, B., Amlouk, A., Boubaker, K., \& Amlouk, M. (2014). Study of nickel doping effects on structural, electrical and optical properties of sprayed $\mathrm{ZnO}$ semiconductor layers. Journal of alloys and compounds, 582, 810-822.

[27] Ajili, M., Castagné, M., \& Turki, N. K. (2013). Study on the doping effect of Sn-doped ZnO thin films. Superlattices and Microstructures, 53, 213-222.

[28] Chahmat, N., Haddad, A., Ain-Souya, A., Ganfoudi, R., Attaf, N., \& Ghers, M. (2012). Effect of Sn doping on the properties of $\mathrm{ZnO}$ thin films prepared by spray pyrolysis.Journal of Modern Physics, 3(11), 17811785. 
[29] Studenikin, S. A., Golego, N., \& Cocivera, M. (1998). Optical and electrical properties of undoped ZnO films grown by spray pyrolysis of zinc nitrate solution. Journal of Applied Physics, 83(4), 2104-2111.

[30] Stewart, J. J. P., (2007). Optimization of Parameters for Semiempirical Methods V: Modification of NDDO Approximations and Application to 70 Elements. J. Mol. Model. 13, 1173-1213.

[31] Frisch, M.J. Trucks, G.W. Schlegel, H.B. Scuseria, G.E. Robb, M.A. Cheeseman, et al. (2009). Gaussian 09, Revision D.01, Gaussian Inc., Wallingford CT.

[32] Matxain, J. M., Fowler, J. E., \& Ugalde, J. M. (2000). Small clusters of II-VI materials: Zn i S i, i= 1-9. Physical Review A, 61(5), 053201.

[33] Muscat, J., Wander, A., \& Harrison, N. M. (2001). On the prediction of band gaps from hybrid functional theory. Chemical Physics Letters, 342(3-4), 397-401.

[34] Carbajo, J., Tolosana-Moranchel, A., Casas, J. A., Faraldos, M., \& Bahamonde, A. (2018). Analysis of photoefficiency in $\mathrm{TiO} 2$ aqueous suspensions: effect of titania hydrodynamic particle size and catalyst loading on their optical properties. Applied Catalysis B: Environmental, 221, 1-8.

[35] Khatoon, S., \& Ahmad, T. (2012). Synthesis, optical and magnetic properties of Ni-doped ZnO nanoparticles. Journal of Materials Science and Engineering B, 2(6), 325-333.

[36] Xiong, D. He, M. Zhang, W. Zhao, W. Wang, Q. \& Feng, Z. (2019). Ab initio study on the electronic and optical properties of B-doped ZnO.Journal of Optoelectronics Advance Materials, 21, 129-135.

[37] Zhao, Z. W., Tay, B. K., Chen, J. S., Hu, J. F., Sun, X. W., \& Tan, S. T. (2005). Optical properties of nanocluster-assembled $\mathrm{ZnO}$ thin films by nanocluster-beam deposition. Applied Physics Letters, 87(25), 251912. 